Check for updates

Cite this: RSC Adv., 2019, 9, 14472

\title{
Translation of ceragenin affinity for bacteria to an imaging reagent for infection $\uparrow$
}

\author{
Nilantha Bandara, $\dot{t}^{\mathrm{a}}$ Yubo Li,,$_{\dagger}^{\mathrm{b}}$ Philipp Diebolder, ${ }^{\mathrm{a}}$ Cedric Mpoy, ${ }^{\mathrm{a}}$ Xiaobo Gu, ${ }^{\mathrm{b}}$ \\ Pitambar Khanal, ${ }^{b}$ Shenglou Deng, ${ }^{b}$ Buck E. Rogers ${ }^{a}$ and Paul B. Savage (D)*b
}

\begin{abstract}
Responses to bacterial infections may be manifest systemically without evidence of the location of the infection site. A rapid means of pinpointing infection sites would be useful in providing effective and possibly localized treatment. Successful means of identifying infection sites would require two components: (1) a molecule capable of recognizing bacteria and (2) a means of communicating recognition. For the recognition element, we used a ceragenin, a small molecule with affinity for bacterial membranes that was designed as a mimic of endogenous antimicrobial peptides. For the communication element, we used ${ }^{64} \mathrm{Cu}$, which is a positron emitter. By conjugating a copper chelating group to the ceragenin, the two elements were combined. Chelation of ${ }^{64} \mathrm{Cu}$ by the conjugate was effective and provided a stable complex that allowed in vivo imaging. When administered to mice in a thigh infection model, the ${ }^{64} \mathrm{Cu}$-labeled conjugate accumulated at the site of infection (right thigh) without accumulation at the complementary site (left thigh). This conjugate may provide a means of identifying infection sites in patients presenting general signs of infection without localized symptoms.
\end{abstract}

Received 22nd March 2019

Accepted 17th April 2019

DOI: 10.1039/c9ra02226k

rsc.li/rsc-advances bacteria. $^{4}$ Similarly, endogenous antimicrobial peptides (AMPs) associate with Gram-negative ${ }^{5}$ and Gram-positive bacteria. ${ }^{6}$ Ceragenins are small molecule mimics of AMPs, and they also display affinity for Gram-negative and positive bacteria, specifically bacterial membrane components lipid $A^{6-8}$ and lipotechoic acid. ${ }^{6}$ Due to the relatively simple structures of ceragenins, they can be readily modified, and one such modification has allowed them to be attached to silver nanoparticles.9,10 Silver nanoparticles, coated with a ceragenin, were placed in the presence of bacteria, and confocal imaging showed the ceragenin-appended nanoparticles associated with bacteria. This association was attributed to the affinity of the appended ceragenin for the bacterial membrane components. In a related study, the association of a fluorophore-appended ceragenin with intact cells showed that the ceragenin displayed selectivity for bacterial cells over eukaryotic cells. ${ }^{7}$

Nuclear medicine techniques such as positron emission tomography (PET) and single photon computed tomography (SPECT) have become a primary means of visualizing tumours and inflammation due to their high levels of sensitivity, low background interference and the three-dimensionality of their images. Some SPECT agents have been developed that allow imaging of infection. For example, ${ }^{67} \mathrm{Ga}$-citrate binds to bacteria, but it does not discriminate between bacterial infections and proteins that accumulate at sites of inflammation. ${ }^{\mathbf{1 1 , 1 2}}$ Similarly, ${ }^{99 \mathrm{~m}}$ Tc-labeled compounds have been used to label leukocytes for infection/inflammation imaging; however, these have been shown to be non-specific for bacterial infections. ${ }^{\mathbf{1 3 , 1 4}}$

\footnotetext{
${ }^{a}$ Department of Radiation Oncology, Washington University School of Medicine, St. Louis, MO 63108, USA

${ }^{b}$ Brigham Young University, Department of Chemistry and Biochemistry, Provo, UT 84602, USA. E-mail: paul_savage@byu.edu

$\dagger$ Electronic supplementary information (ESI) available: Details of imaging experiments and syntheses of title compounds. See DOI: 10.1039/c9ra02226k

\$ Contributed equally.
} 
The use of radiolabeled antibiotics such as ciprofloxacin and kanamycin has also suffered from a lack of specificity to date. ${ }^{15}$ Radiolabeled AMPs, such as ubiquicidin, human lactoferrin, and human $\beta$-defensin-3, also appear promising. ${ }^{15}$

As mimics of AMPs and due to their simplicity and insensitivity to proteases, we reasoned that ceragenins might be well suited for imaging of infections. By conjugating a ceragenin (bacteria targeting) to an appropriate metal chelating group (for complexing a positron-emitting radiometal), we generated compounds with features necessary for selectively imaging infections. In initial studies of infection imaging, ceragenins were non-specifically labelled with ${ }^{99 \mathrm{~m}} \mathrm{Tc}$ and successfully imaged an infection (Staphylococcus aureus) model in rats. ${ }^{16}$ However, the nature of the ceragenin-technetium complex was not well established. Additionally, ceragenins display higher cell selectivity for Gram-negative bacteria (e.g., Escherichia coli) over Gram-positive organisms (e.g., S. aureus). Consequently, we anticipated that Gram-negative infections would be preferentially labelled by ceragenin conjugates.

Conjugates of a ceragenin with 1,4,7-triazacyclononane1,4,7-triacetic acid (NOTA) were prepared, along with structural variants, and these were stably labelled with ${ }^{64} \mathrm{Cu}$ and injected into mice. Distribution of the labelled compounds was determined in un-infected mice and in mice with a local thigh infection. ${ }^{64} \mathrm{Cu}$-labeled conjugates derived from a ceragenin accumulated in the infected muscle in significantly greater amounts than structural variants lacking a ceragenin. The presence of a $\mathrm{C}_{8}$ lipid chain on a ceragenin-containing conjugate increased the lipophilicity of the compound but did not significantly alter accumulation of the conjugate in infected muscle.

\section{Results and discussion}

We have found that lipid chains extending from the nitrogen on C24 of ceragenins impact their antimicrobial properties. ${ }^{17}$ Consequently, two different forms of ceragenin were used as bacterial membrane recognition elements: one without a lipid chain (1) and one with an octyl chain (2) (Fig. 1). NOTA was used

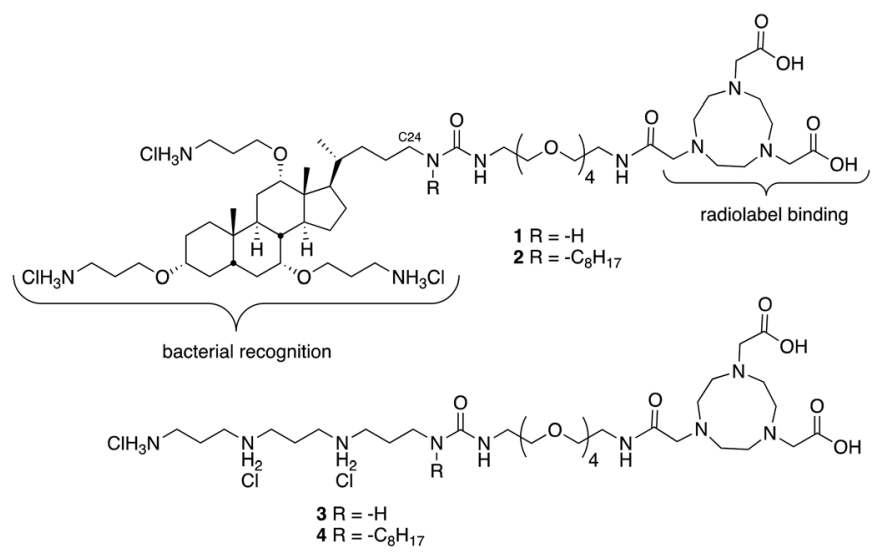

Fig. 1 Structures of ceragenin-NOTA conjugates 1 and 2 and structural variants 3 and 4 . for binding ${ }^{64} \mathrm{Cu}$, which is a positron emitter with a 12.7 hour half-life. NOTA has been well characterized as a thermodynamically and kinetically stable copper binding ligand suitable for conjugating to a variety of targeting groups..$^{18}$ An oligo-ethylene glycol linker was used to separate the ceragenin and NOTA to ensure that the bound copper ion did not interfere with interactions with bacterial membranes. In efforts to determine the structural features of conjugates 1 and $\mathbf{2}$ that impact bacterial labelling and imaging, structural variants 3 and $\mathbf{4}$ were prepared. Variants $\mathbf{3}$ and $\mathbf{4}$ retain three positive charges and lack the bile acid backbone found in $\mathbf{1}$ and $\mathbf{2}$. The absence ( $\mathbf{1}$ and $\mathbf{3}$ ) or presence ( 2 and $\mathbf{4}$ ) of an octyl lipid chain was used to determine its role in association with bacteria.

To generate desired conjugates $\mathbf{1}$ and $\mathbf{2}$, amines $\mathbf{5 a}$ and $\mathbf{5 b}^{\mathbf{7}}$ (Scheme 1) were reacted with phenylcarbamate 6 to give $7 \mathbf{a}$ and $7 \mathbf{b}$ in reasonable yields. The azide groups in $7 \mathbf{a}$ and $7 \mathbf{b}$ were reduced to the corresponding amines, which were reacted with bis-Boc NOTA, using COMU as a coupling agent. Deprotection of both the carbamates and the $t$-butyl esters with hydrogen chloride in dioxane gave $\mathbf{1}$ and 2.

For generation of 3 and $\mathbf{4}$ the steps outlined in Scheme 2 were followed. Alcohol in $\mathbf{8}$ (prepared using methods described in ref. 19) was converted to the mesylate and then to either the corresponding amine 9a or octylamine 9b. Coupling with the PEG tether 6 gave 10a and 10b, which were reduced and coupled with NOTA to give 3 and 4.

Conjugates 1-4 were loaded with ${ }^{64} \mathrm{Cu}^{2+}\left(\mathrm{CuCl}_{2}\right)$ to give the corresponding complexes, which were analysed via reversedphase HPLC. Radiochemical purity was determined as $98 \pm$ $1.3 \%$, and specific activity was maintained at $c a .20 \mu \mathrm{Ci} \mu \mathrm{g}^{-1}$ for all compounds. As shown in Fig. 2, copper-labelled, cerageninNOTA conjugates 1 and $2\left({ }^{64} \mathrm{Cu}-1\right.$ and $\left.{ }^{64} \mathrm{Cu}-2\right)$ gave retention times of 12.0 and $15.4 \mathrm{~min}$, respectively, without loss of the copper label (i.e., free copper was not detected). To the extent that retention times on a $\mathrm{C}_{18}$ silica chromatography column provide information about the lipophilicity of analytes, labelled structural variants 3 and $4\left({ }^{64} \mathrm{Cu}-3\right.$ and $\left.{ }^{64} \mathrm{Cu}-4\right)$ proved to have lipophilicities comparable to and less than those of ${ }^{64} \mathrm{Cu}-\mathbf{1}$ and ${ }^{64} \mathrm{Cu}-2$

To further demonstrate the stability of the complexes, studies were conducted in human serum to investigate potential degradation of the radiolabeled compounds. The stability of ceragenin complexes was determined by measuring the

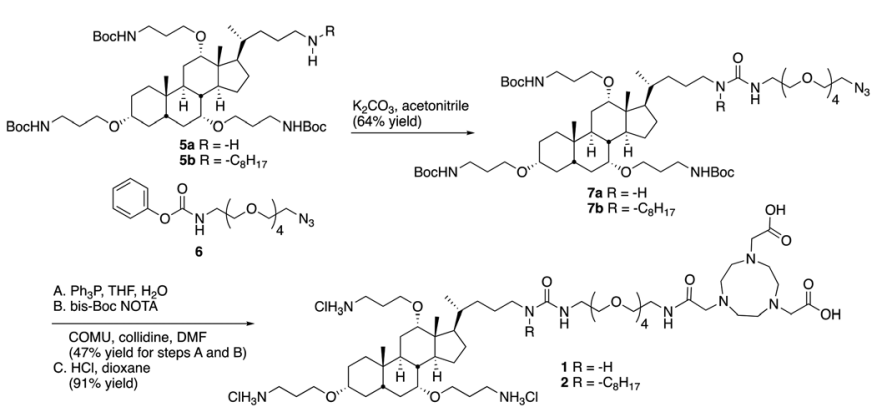

Scheme 1 Preparation of ceragenin-NOTA conjugates 1 and 2. 


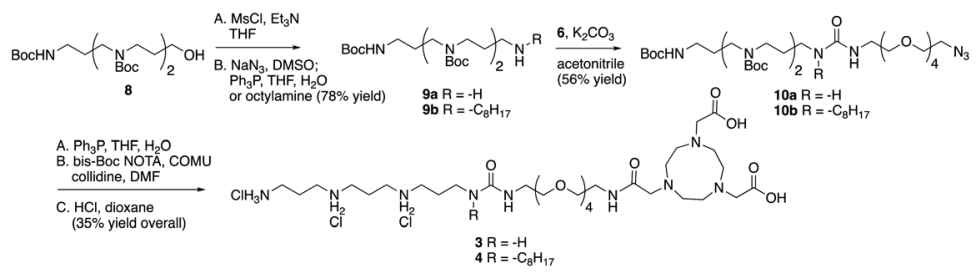

Scheme 2 Preparation of tri-ammonium-NOTA conjugates 3 and 4 .

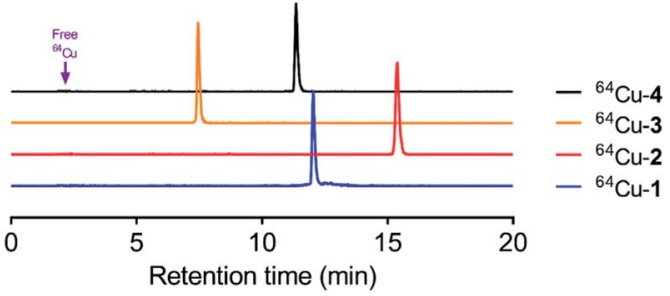

Fig. 2 HPLC chromatograms of ${ }^{64} \mathrm{Cu}$ radiolabeled compounds. Retention times were $12.02,15.4,7.5$ and $11.3 \mathrm{~min}$ for ${ }^{64} \mathrm{Cu}-1,{ }^{64} \mathrm{Cu}-2$, ${ }^{64} \mathrm{Cu}-3$ and ${ }^{64} \mathrm{Cu}-4$, respectively. If present, free copper would appear at $2.5 \mathrm{~min}$.

radioactive fraction of the parent compound at incubation intervals in human serum at $37^{\circ} \mathrm{C}$. No unbound metal was observed over the evaluation time indicating that the complex remained $100 \%$ intact up to $4 \mathrm{~h}$.

To determine the relative uptake and retention of the conjugates, biodistribution experiments were conducted in CD1 mice with labeled 1-4 (Table S1 $\dagger$ ). All animal procedures were performed in accordance with the Guidelines for Care and Use of Laboratory Animals of Washington University and experiments were approved by the Animal Ethics Committee of Washington University. The most substantial differences in uptake and retention among the conjugates were that ${ }^{64} \mathrm{Cu}-1$ and ${ }^{64} \mathrm{Cu}-2$ were retained in the liver in higher relative amounts than ${ }^{64} \mathrm{Cu}-3$ and ${ }^{64} \mathrm{Cu}-\mathbf{4}$, and that ${ }^{64} \mathrm{Cu}-\mathbf{1}$ was retained in the kidney in higher relative amounts than ${ }^{64} \mathrm{Cu}-2$.

We used a model of thigh muscle infection with Escherichia coli (TG1) in CD-1 mice to evaluate the impact of infection on distribution of the conjugates. The infection was established $24 \mathrm{~h}$ before injection of the conjugates. The primary measure of uptake was percentage of injected dose per gram in each type of tissue (\% ID per g). We previously observed high affinity of ceragenins for the outer membranes of Gram-negative bacteria, including the lipid A portion of lipopolysaccharide, ${ }^{6,7}$ and it was anticipated that this affinity would result in accumulation of the conjugates at the site of infection. Similar to the uninfected mice (Table S1 $\dagger$ ), ${ }^{64} \mathrm{Cu}-\mathbf{1}$ and ${ }^{64} \mathrm{Cu}-\mathbf{2}$ accumulated in the liver and kidney, relative to ${ }^{64} \mathrm{Cu}-3$ and ${ }^{64} \mathrm{Cu}-4$ (Fig. 3) of infected mice. Uptake values for labelled conjugates in the left thigh muscle (control, no bacteria) were not significantly different (Fig. 3B). Uptake in the right thigh muscle, containing the bacterial infection, was highest with ${ }^{64} \mathrm{Cu}-1(1.86 \pm 0.78 \%$ ID perg) and was lowest with ${ }^{64} \mathrm{Cu}-3(0.26 \pm 0.07 \%$ ID per g) with a $\mathrm{p}$ value of 0.008 . The uptake of ${ }^{64} \mathrm{Cu}-2$ was also significantly increased relative to ${ }^{64} \mathrm{Cu}-3$ and ${ }^{64} \mathrm{Cu}-4$.
Based on the biodistribution results, ${ }^{64} \mathrm{Cu}-\mathbf{1}$ was selected for more detailed autoradiography studies of infections sites. Thigh infections (E. coli) were generated in mice as described above, and muscles were removed, sectioned, and imaged. Uptake of ${ }^{64} \mathrm{Cu}-\mathbf{1}$ was much higher in the infected thigh muscles compared to the control left thigh (Fig. 4). This significant difference $(p<0.0001)$ was quantified by recording the number of counts per $\mathrm{mm}^{2}$ from the sections and these values are given in Fig. 5A. A comparison of the \% ID per $\mathrm{g}$ of ${ }^{64} \mathrm{Cu}-1$ in abdominal and thigh muscles is given in Fig. 5B. Further comparison was from in vivo measurement of standardized uptake values (SUVs), which are ratios of the image-derived radioactivity concentration and the whole-body concentration of injected radioactivity. With this measurement, there is no significant difference between the uptake of ${ }^{64} \mathrm{Cu}-1$ in uninfected thigh muscle and peripheral muscle, while the difference between uptake in infected and uninfected muscle is significant $(p=0.0064)$ (Fig. 5C).

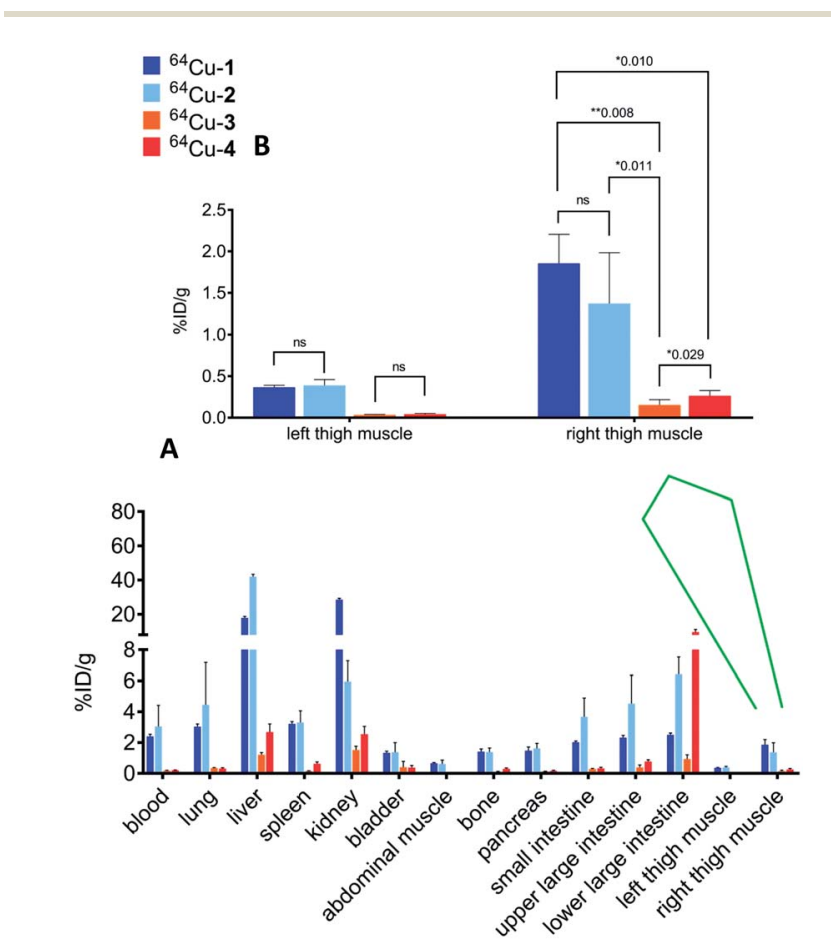

Fig. 3 (A) Overall biodistribution results (\% ID per g) of ${ }^{64} \mathrm{Cu}-1,{ }^{64} \mathrm{Cu}-2$, ${ }^{64} \mathrm{Cu}-3$ and ${ }^{64} \mathrm{Cu}-4$ in $\mathrm{CD}-1$ mice with intramuscular infection in right thigh muscle at $4 \mathrm{~h}$ post injection. (B) Expansion of plot of data from left and right thigh muscles. 


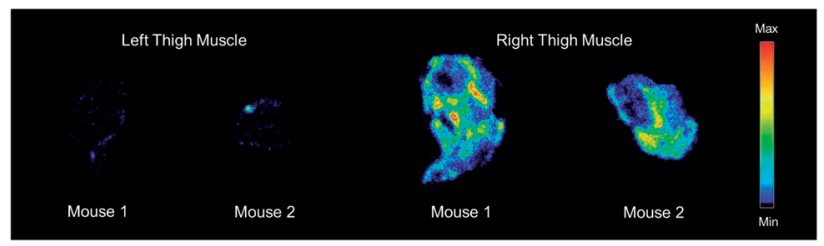

Fig. 4 Representative images from ex vivo autoradiography of left and right thigh muscle sections $(20-40 \mu \mathrm{m})$ from ${ }^{64} \mathrm{Cu}-1$ in CD-1 mice, at $4 \mathrm{~h}$ post injection. (a)

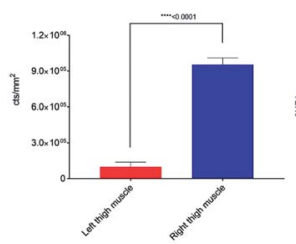

(b)

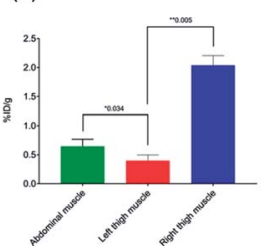

(c)

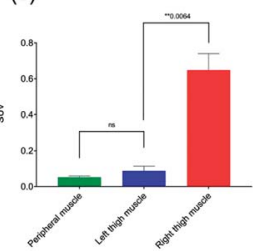

Fig. 5 Comparisons of ${ }^{64} \mathrm{Cu}-1$ uptake in CD-1 mice with an intramuscular infection ( $E$. coli) in the right thigh at $4 \mathrm{~h}$ post injection. (a) Quantitative results (counts per $\mathrm{mm}^{2}$ ) of ${ }^{64} \mathrm{Cu}-1$ in an ex vivo autoradiography study with left and right thigh muscle sections (20-40 $\mu \mathrm{m}, n$ $=9$ sections per muscle). (b) Abdominal vs. thigh muscle uptake of ${ }^{64} \mathrm{Cu}-1$ in \% ID per g. (c) SUV (standardized uptake value) calculations from in vivo imaging comparing peripheral and thigh muscle.

In biodistribution studies of ${ }^{64} \mathrm{Cu}-\mathbf{1}$ (Fig. 3), we saw accumulation of the conjugate in the liver and kidneys, and with in vivo imaging we saw similar accumulation. A representative image of PET static data in CD-1 mice with infection in the right thigh is shown in Fig. 6. Along with a kidney and liver uptake, the PET image gave a clear indication of specific infection labelling of the right thigh compared to the left.

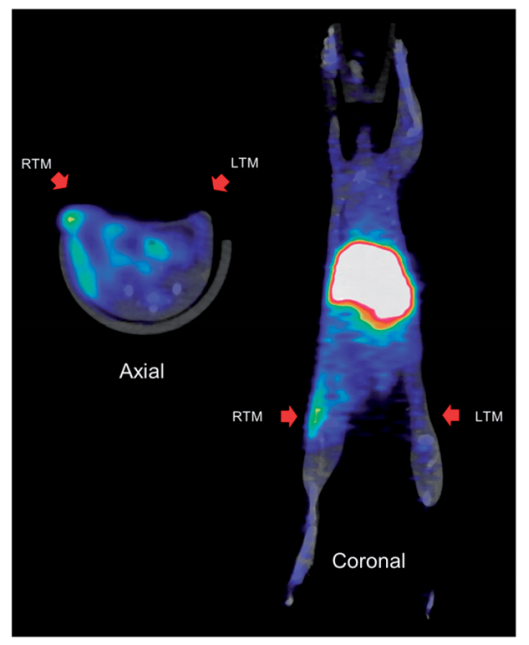

Fig. 6 Representative coronal and axial PET images of ${ }^{64} \mathrm{Cu}-1$ in athymic nude mice, with intramuscular infection in right thigh muscle, at $4 \mathrm{~h}$ post injection. Left and right thigh muscles indicated in the figure in red arrows.

\section{Conclusions}

Lipopolysaccharide is the primary constituent of the outer membranes of Gram-negative bacteria, and the lipid A structure is well conserved among bacteria. Consequently, lipid A is a logical target for bacterial recognition. We have measured the $K_{\mathrm{d}}$ of the base structure of ceragenins for the lipid A portion of lipopolysaccharide as $0.59 \mu \mathrm{M},{ }^{7}$ and the affinity of this structure for lipid A is greater than that of polymyxin B, the paradigm of small molecule binding of lipid A. The affinity of ceragenins for lipid A is consistent with measurements of interactions of the ceragenin base structure for intact cells; a labelled ceragenin was shown to preferentially associate with Gram-negative bacteria over Gram-positive bacteria and eukaryotic cells. ${ }^{7}$ Translation of affinity of ceragenins to imaging of infection poses a challenge due to the complex environments provided by in vivo applications including higher numbers of eukaryotic cells relative to prokaryotes. Nevertheless, by conjugating ceragenins to NOTA and loading with ${ }^{64} \mathrm{Cu}$, we have generated compounds that selectively label infected tissue in mice. These conjugates display the expected ability to bind ${ }^{64} \mathrm{Cu}$ while retaining affinity for bacteria. This affinity allows selective labelling of bacteria and may provide a means of identifying sites of infection in patients that display associated symptoms without indications of localized infection.

\section{Conflicts of interest}

PBS is a paid consultant for CSA Biotechnologies, Inc. Other authors declare no competing financial interest.

\section{Acknowledgements}

The authors would like to thank the small animal imaging facility at Washington University School of Medicine for excellent technical assistance in conducting biodistribution and small animal imaging studies. We would also like to acknowledge the Isotope Production Group at Washington University for the routine production of ${ }^{64} \mathrm{Cu}$. This research was supported by the National Institutes of Health (R21AI120673).

\section{References}

1 O. H. Arenholz and R. L. Simmons, Pancreatitis and other intraabdominal infections, in Surgical Infectious Disease, ed. H. R. J. Simmons, Appleton \& Lang, Norwalk, CT, 2nd edn, 1988, pp. 605-46.

2 P. A. Pizzo, Evaluation of fever in the patient with cancer, Eur. J. Cancer Clin. Oncol., 1989, 25, S9-S16.

3 G. Ferro-Flores, B. E. Ocampo-Garcia and L. MelendezAlafort, Development of specific radiopharmaceuticals for infection imaging by targeting infectious micro-organisms, Curr. Pharm. Des., 2012, 18, 1098-1106.

4 C. J. Thomas, N. Surolia and A. Surolia, Surface plasmon resonance studies resolve the enigmatic endotoxin neutralizing activity of polymyxin B, J. Biol. Chem., 1999, 274, 29624-29627. 
5 U. H. N. Dürr, U. S. Sudheendra and A. Ramamoorthy, LL-37, the only human member of the cathelicidin family of antimicrobial peptides, Biochim. Biophys. Acta, 2006, 1758, 1408-1425.

6 E. Isogai, H. Isogai, K. Takahashi, K. Okumura and P. B. Savage, Ceragenin CSA13 exhibits antimicrobial activity against cariogenic and periodontopathic bacteria, Oral Microbiol. Immunol., 2009, 24, 170-172.

7 B. Ding, N. Yin, Y. Liu, J. Cardenas-Garcia, R. Evanson, R. Orsak, M. Fan, G. Turin and P. B. Savage, Origins of cell selectivity of cationic steroid antibiotics, J. Am. Chem. Soc., 2004, 126, 13642-13648.

8 R. Bucki, A. G. Sostarecz, F. J. Byfield, P. B. Savage and P. A. Janmey, Resistance of the antibacterial agent ceragenin CSA-13 to inactivation by DNA of F-actin, and its activity in cystic fibrosis sputum, J. Antimicrob. Chemother., 2007, 60, 535-545.

9 M. A. Hoppens, C. B. Sylvester, A. T. Qureshi, T. Scherr, D. R. Czaps, R. S. Duran, P. B. Savage and D. Hayes, Ceragenin mediated selectively of antimicrobial silver nanoparticles, ACS Appl. Mater. Interfaces, 2014, 6, 1390013908.

10 M. A. Hoppens, Z. E. W. Wheeler, A. T. Qureshi, K. Hogan, A. Wright, G. G. Stanley, D. Young, P. B. Savage and D. Hayes, Maghemite, silver, ceragenin conjugate particles for selective binding and contrast of bacteria, J. Colloid Interface Sci., 2014, 413, 167-174.

11 W. Y. Lin, T. H. Chao and S. J. Wang, Clinical features and gallium scan in the detection of post-surgical infection in the elderly, Eur. J. Nucl. Med. Mol. Imaging, 2002, 29, 371-375.
12 H. J. Rennen, O. C. Boerman, W. J. Oyen and F. H. Corstens, Imaging infection/inflammation in the new millenium, Eur. J. Nucl. Med., 2001, 28, 241-252.

13 M. Welling, H. I. Feitsma, W. Calame and E. K. Pauwels, Detection of experimental infections with 99mTc-labeled monoclonal antibodies against TNF- $\alpha$ and interleukin-8, Nucl. Med. Biol., 1997, 24, 649-655.

14 P. S. Rao, V. R. Pallela, D. Vassileva-Belnikolovska, D. Jungkind and M. L. Thakur, A receptor-specific peptide for imaging infection and inflammation, Nucl. Med. Commun., 2000, 21, 1063-1070.

15 M. M. Welling, G. Ferro-Flores, I. Pirmettis and C. Brouwer, Current status of imaging infections with radiolabelled antiinfective agents, Anti-Infect. Agents Med. Chem., 2009, 8, 272287.

16 S. Roohi, N. Amir, M. Ahmed, P. B. Savage, S. M. Saluhiddin and M. Jehangir, Synthesis, quality control and biological evaluation of ${ }^{99 \mathrm{~m}_{\mathrm{Tc}}}$ labeled CSA-13, J. Radioanal. Nucl. Chem., 2009, 97, 57-62.

17 C. Li, L. P. Budge, C. D. Driscoll, B. M. Willardson, G. W. Allman and P. B. Savage, Incremental conversion of outer-membrane permeabilizers into potent antibiotics for Gram-negative bacteria, J. Am. Chem. Soc., 1999, 121, 931940.

18 V. Kubícek, Z. Böhmová, R. Sevciková, J. Vanek, P. Lubal, Z. Poláková, R. Michalicová, J. Kotek and P. Hermann, NOTA complexes with copper(II) and divalent metal ions: kinetic and thermodynamic studies, Inorg. Chem., 2018, 57, 3061-3072.

19 K. Skruber, K. J. Chaplin and O. Phanstiel IV, Synthesis and bioevaluation of macrocycle-polyamine conjugates as cell migration inhibitors, J. Med. Chem., 2017, 60, 8606-8619. 